\title{
Hyperthermia-induced in situ drug amorphization by superparamagnetic nanoparticles in oral dosage
}

\author{
forms \\ Shaquib Rahman Ansari, Nele-Johanna Hempel, Shno Asad, Peter Svedlindh, Christel A. S. \\ Bergström, Korbinian Löbmann, and Alexandra Teleki*
}

Shaquib Rahman Ansari - Department of Pharmacy, Science for Life Laboratory, Uppsala University, 75123 Uppsala, Sweden

Nele-Johanna Hempel ${ }^{\dagger}-$ Department of Pharmacy, University of Copenhagen, 2100 Copenhagen, Denmark

Shno Asad - Department of Pharmacy, Science for Life Laboratory, Uppsala University, 75123 Uppsala, Sweden

Peter Svedlindh - Department of Materials Science and Engineering, Uppsala University, 75103 Uppsala, Sweden

Christel A. S. Bergström - Department of Pharmacy, Uppsala University, 75123 Uppsala, Sweden 
Korbinian Löbmann - Department of Pharmacy, University of Copenhagen, 2100 Copenhagen, Denmark

Alexandra Teleki - Department of Pharmacy, Science for Life Laboratory, Uppsala University, 75123 Uppsala, Sweden

KEYWORDS: superparamagnetic nanoparticles, oral drug delivery, in situ drug amorphization, amorphous solid dispersions, magnetic hyperthermia

ABSTRACT: Superparamagnetic iron oxide nanoparticles (SPIONs) generate heat upon exposure to an alternating magnetic field (AMF) which has been studied for hyperthermia treatment and triggered drug release. This study introduces a novel application of magnetic hyperthermia to induce amorphization of a poorly aqueous soluble drug, celecoxib, in situ in tablets for oral administration. In situ amorphization can overcome the drug development hurdle of poor aqueous solubility by molecularly dispersing the drug in a polymeric network inside a tablet. However, current shortcomings of this approach include low drug loading in the tablets, toxicity of enabling excipients, and drug degradation. Here, SPIONs produced by flame spray pyrolysis are compacted with polyvinylpyrolidone and celecoxib, and exposed to an AMF. The degree of amorphization is strongly linked to the maximum tablet temperature achieved during AMF exposure, which depends on SPION composition and content in the tablets. Manganese ferrites exhibit no toxicity in human intestinal Caco-2 cell lines and are more effective than zinc ferrites in inducing complete amorphization of celecoxib. The resulting rapid dissolution and high solubility of in situ amorphized celecoxib in biorelevant intestinal fluid demonstrates the promising capability of SPIONs as enabling excipients to magnetically induce amorphization in situ in oral dosage forms. 


\section{INTRODUCTION}

Poor aqueous drug solubility, and the resulting low bioavailability and potential lack of therapeutic effect, is a major challenge in oral drug delivery. One strategy to increase solubility and dissolution rate is conversion of the crystalline drug into its amorphous form. ${ }^{1}$ However, the amorphous forms are thermodynamically unstable and require stabilization to avoid recrystallization during storage or after in vivo administration. The drug is therefore commonly formulated as an amorphous solid dispersion (ASD) in which it is molecularly dispersed in a polymeric network. The polymer in the ASD stabilizes the drug in the solid state and thereby inhibits recrystallization during storage. Further, it may prevent (or delay) drug precipitation upon dissolution and improve solubility. This results in fast dissolution where the subsequent maintenance of supersaturated drug concentrations in vivo can drive absorption from the gastrointestinal tract. ${ }^{1-3}$ Oral dosage forms comprising ASDs have been successfully marketed, e.g. Venclexta, which is used to treat diseases such as chronic lymphocytic leukemia, and acute myeloid leukemia, and contains venetoclax as the active pharmaceutical ingredient and polyvinyl alcohol as the enabling excipient.

However, despite the proven advantages of ASDs, several short-comings hinder the successful translation of more ASD-based dosage forms to the market. ${ }^{3,4}$ The drug load in stable ASDs is typically low $(10-30 \mathrm{wt} \%)$ as it is limited by the drug solubility in the polymer at storage

temperature, ${ }^{2,5}$ this in turn means that the size of the dosage form increases when a higher drug dose is required, with negative implications for the patient. Furthermore, many polymers commonly used as ASD excipients, such as polyvinylpyrrolidone (PVP) are hygroscopic. Such excipients increase the molecular mobility in the ASDs due to the plasticizing effect of adsorbed 
water, and hence, can induce amorphous-amorphous phase separation and ultimately recrystallization of the drug during storage. Finally, amorphous powders exhibit poor flowability in pharmaceutical tableting equipment. As a result, ASD manufacturing requires additional processing steps, such as granulation, which increases the complexity and cost of production.

In situ amorphization has been recently introduced to overcome the challenges of drug load, stability and manufacturing of ASDs. ${ }^{6}$ In situ amorphization can overcome storage stability issues of ASDs and allows for higher drug loadings (up to $50 \mathrm{wt} \%$ ) than what is dictated by the thermodynamic solubility limit of the drug in the polymer at storage temperature since storage times can be kept short. ${ }^{7,8}$ Amorphization and ASD formation take place in the final dosage form either directly after tablet manufacturing or before administration to the patient, e.g. at hospital pharmacies. ${ }^{9}$ The tablet for in situ amorphization is produced by established pharmaceutical tableting protocols such as direct compaction of a crystalline drug in a polymer mixture. The ASD is then formed in situ by exposing the tablet to a radiation source, e.g. microwave ${ }^{9,10}$ or laser. ${ }^{8}$ This is a time- and temperature-dependent process, whereby the radiation increases the tablet temperature and the drug dissolves in the polymer at temperatures above the glass transition temperature $\left(T_{\mathrm{g}}\right)$ of the polymer. ${ }^{7,11}$ Amorphization by microwave radiation requires excipients, such as glycerol or water in the tablets. ${ }^{9}$ Large amounts (approx. $20 \mathrm{wt} \%$ ) of the enabling excipients have to be added to reach complete amorphization, which hampers the mechanical properties of the tablet. The laser-induced approach uses plasmonic nanoparticles (Ag) as the enabling excipient and only requires as low as $0.1 \mathrm{wt} \%$ of them in the tablets. ${ }^{8}$ However, the penetration depth of the laser in the tablet is limited and not uniform, making the scale-up difficult. Furthermore, the use of plasmonic nanoparticles maybe toxic upon repeated administration to patients due to their dose 
dependent toxicity. ${ }^{12}$ Thus, there is a need to identify other effective and safe in situ amorphization excipients.

Superparamagnetic iron oxide nanoparticles (SPIONs) could overcome the shortcomings of current in situ amorphization methods by using magnetic hyperthermia. SPIONs $\left(\mathrm{Fe}_{3} \mathrm{O}_{4}\right.$ or $\gamma-\mathrm{Fe}_{2} \mathrm{O}_{3}$ ) are non-toxic, biocompatible, biodegradable and efficiently cleared from the body via the iron metabolism pathway. ${ }^{13}$ They are approved by the US Food and Drug Administration (FDA) as oral magnetic resonance imaging contrast agents (Ferumoxsil) and for treatment of anemia (Ferumoxytol) in patients with chronic kidney disease. ${ }^{14}$

SPIONs release heat locally upon exposure to an alternating magnetic field (AMF) due to relaxation losses. The heat dissipation from SPIONs on exposure to an AMF is the result of relaxation of the magnetic moment within the particle (Néel relaxation) or the rotation of the particle itself (Brownian relaxation). ${ }^{15}$ So far, this property of SPIONs, commonly termed magnetic hyperthermia, has been used for treatment of cancer ${ }^{16,17}$ and triggered drug delivery. ${ }^{18}$ The heat dissipation properties can be enhanced by careful engineering of the SPION properties, e.g., with unidirectional growth of nanoparticles, doping with metals, size optimization, and formation of nanocrystal clusters. ${ }^{19-21}$ In particular, spinel crystal nanostructures of e.g. iron oxide doped with $\mathrm{Zn}^{2+}$ or $\mathrm{Mn}^{2+}$ release more heat than pure iron oxides. ${ }^{22,23}$ 


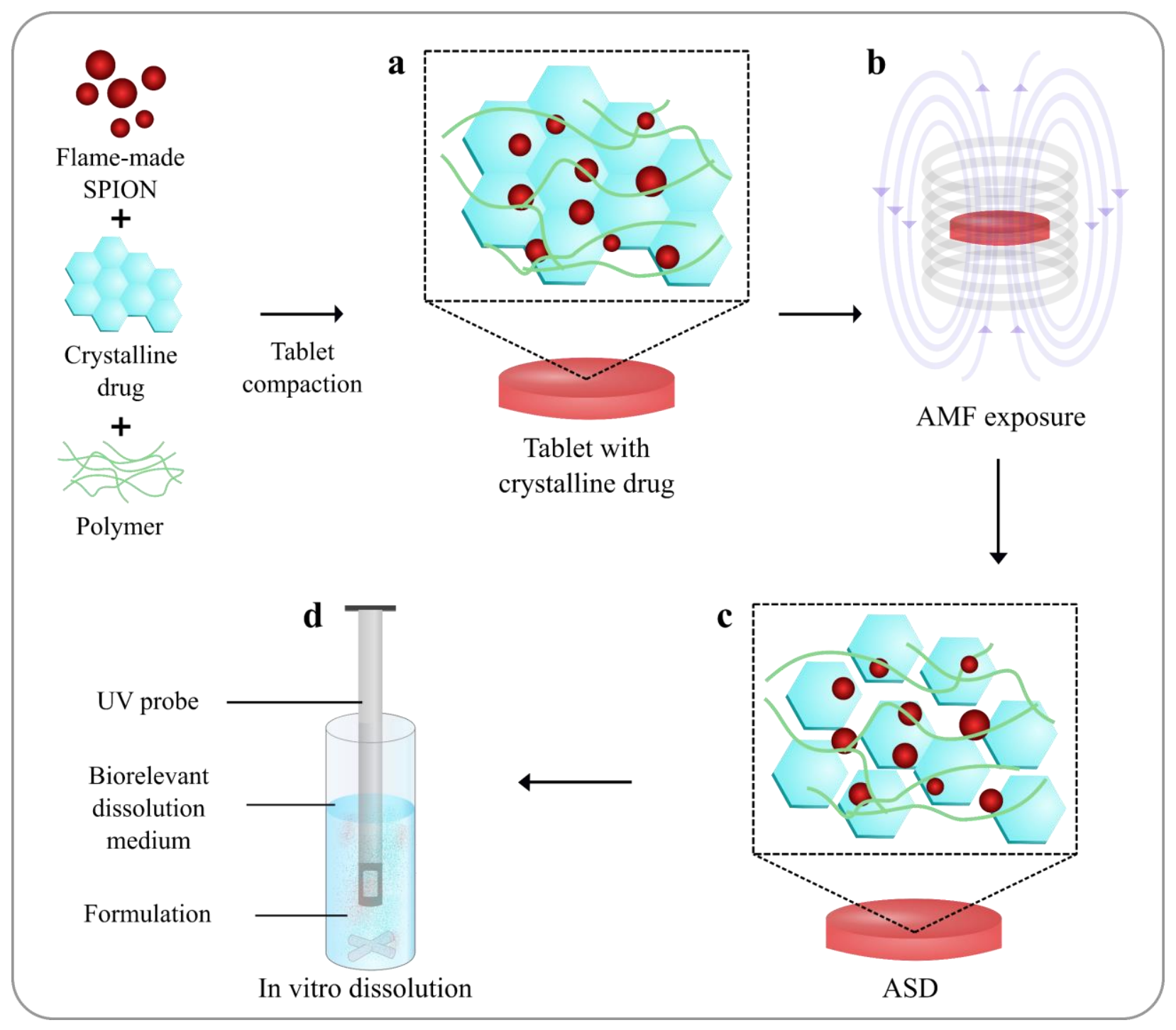

Figure 1. Amorphization by magnetic hyperthermia of a poorly aqueous soluble, crystalline drug in a tablet. The crystalline drug is compacted into tablets with flame-made superparamagnetic iron oxide nanoparticles (SPIONs) and a polymer (a). The tablets are exposed to an alternating magnetic field (AMF) (b) to form an amorphous solid dispersion (ASD; c). Performance of the ASD is evaluated by an in vitro dissolution assay (d).

In this work, we demonstrate for the first time the use of SPIONs to induce amorphization of a poorly aqueous soluble crystalline drug (celecoxib), in tablets for oral administration (Figure 1). Celecoxib, a cyclooxygenase-2 inhibitor widely used to treat osteoarthritis and rheumatoid 
arthritis, ${ }^{24}$ was chosen as the model drug due to its low aqueous solubility and poor bioavailability. Because of this, high doses are required for oral administration, which causes adverse side effects in the gastrointestinal tract. The doped SPIONs were produced by flame spray pyrolysis (FSP), ${ }^{23,25}$ a bottom-up nanomanufacturing technique with proven scalability and reproducibility. ${ }^{26,27}$ The structural, morphological, magnetic and heating properties of the FSP-made SPIONs were characterized and their cytotoxicity on human Caco-2 intestinal cells assessed. A Design of Experiments (DoE) approach was applied to systematically investigate the effects of nanoparticle and tablet composition, and AMF exposure time on the degree of drug amorphization in the tablets. Finally, the dissolution behavior of the tablets containing SPIONs was evaluated in vitro in biorelevant simulated intestinal fluids. This study thus reports a novel application of SPIONinduced magnetic hyperthermia to improve oral drug delivery of a poorly aqueous soluble drug candidate.

\section{RESULTS AND DISCUSSION}

Nanoparticle Properties. Zinc and manganese ferrites were prepared by flame spray pyrolysis (FSP) and investigated as enabling excipients for in situ amorphization in tablets containing celecoxib. Flame process parameters were set to produce nanoparticles with primary particle sizes in the range of 12-20 $\mathrm{nm}$. This size range has been reported, both experimentally and computationally, to result in maximum heating efficiency during hyperthermia. ${ }^{28-31}$ Table S1 summarizes nanoparticle size, magnetization, and heating efficiency in an AMF of as-produced SPION powders. Pure iron oxide is included for comparison. 

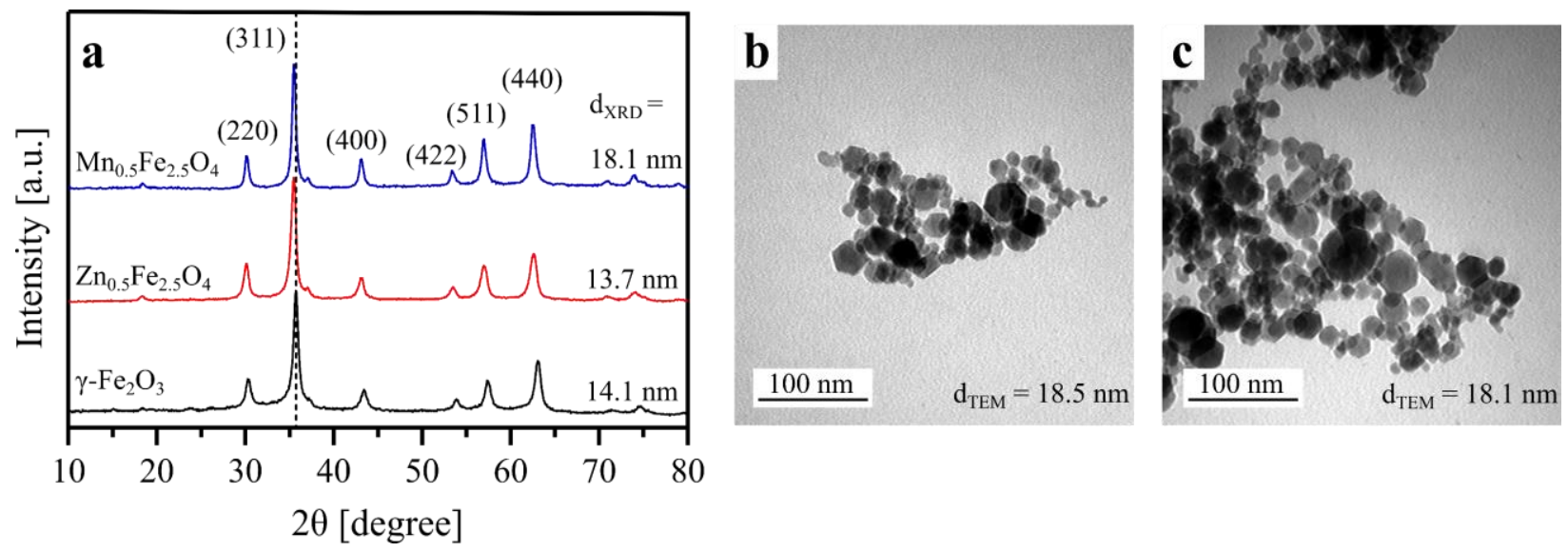

Figure 2. a) XRD patterns of $\gamma-\mathrm{Fe}_{2} \mathrm{O}_{3}$ (black), $\mathrm{Zn}_{0.5} \mathrm{Fe}_{2.5} \mathrm{O}_{4}$ (red) and $\mathrm{Mn}_{0.5} \mathrm{Fe}_{2.5} \mathrm{O}_{4}$ (blue). The dashed line represents the maghemite (311) peak and visualizes the peak shift of the zinc and manganese ferrites. b) and c) Representative TEM images of $\mathrm{Zn}_{0.5} \mathrm{Fe}_{2.5} \mathrm{O}_{4}$ and $\mathrm{Mn}_{0.5} \mathrm{Fe}_{2.5} \mathrm{O}_{4}$, respectively.

Figure $2 \mathrm{a}$ shows the X-ray diffraction (XRD) patterns of pure $\gamma-\mathrm{Fe}_{2} \mathrm{O}_{3}$ and SPION doped with $\mathrm{Zn}^{2+}$ and $\mathrm{Mn}^{2+}$ to form the ferrites, $\mathrm{Zn}_{0.5} \mathrm{Fe}_{2.5} \mathrm{O}_{4}$ and $\mathrm{Mn}_{0.5} \mathrm{Fe}_{2.5} \mathrm{O}_{4}$. The diffractograms correspond to spinel cubic structures, exhibiting six prominent peaks originating from the (220), (311), (400), (422), (511) and (440) crystallographic planes. ${ }^{32,33}$ Pure iron oxide forms $\gamma$ - $\mathrm{Fe}_{2} \mathrm{O}_{3}$ (maghemite), in agreement with previous SPION synthesis in oxygen-rich flames. ${ }^{34}$ Spinel-ferrite structures were formed by the addition of $\mathrm{Zn}^{2+}$ or $\mathrm{Mn}^{2+}$, as evidenced by a slight shift of diffraction peaks towards lower angles (shown in Figure $2 \mathrm{a}$ as the dashed line at the (311) plane). ${ }^{25}$ The peak shift is accompanied with a lattice expansion (Table S1), indicating the successful incorporation of $\mathrm{Zn}^{2+}$ and $\mathrm{Mn}^{2+}$ ions into the $\gamma-\mathrm{Fe}_{2} \mathrm{O}_{3}$ crystal lattice. ${ }^{23,35}$ Furthermore, no diffraction peaks corresponding to pure zinc oxide or manganese oxide were observed. The average crystallite size (dxRD) was about $14 \mathrm{~nm}$ for both $\gamma-\mathrm{Fe}_{2} \mathrm{O}_{3}$ and $\mathrm{Zn}_{0.5} \mathrm{Fe}_{2.5} \mathrm{O}_{4}$ and $18 \mathrm{~nm}$ for $\mathrm{Mn}_{0.5} \mathrm{Fe}_{2.5} \mathrm{O}_{4}$ (Figure 2a). The larger ionic radius of $\mathrm{Mn}^{2+}(0.81 \AA)$ compared to $\mathrm{Fe}^{3+}(0.64 \AA)$ and $\mathrm{Zn}^{2+}(0.74 \AA)$ at the tetrahedral site might explain the increase in crystal size for the manganese ferrite. ${ }^{36,37}$ 
Figure $2 \mathrm{~b}$ and $2 \mathrm{c}$ show representative transmission electron microscopy (TEM) images of $\mathrm{Zn}_{0.5} \mathrm{Fe}_{2.5} \mathrm{O}_{4}$ and $\mathrm{Mn}_{0.5} \mathrm{Fe}_{2.5} \mathrm{O}_{4}$ nanoparticles, respectively. The nanoparticles are polyhedrons with a narrow primary particle size distribution (Figure S1) in excellent agreement with the literature..$^{25,34,38}$ The primary particle size determined from TEM analysis $\left(\mathrm{d}_{\text {TEM }}\right)$ was about $18 \mathrm{~nm}$ for both ferrites, in good agreement with the $\mathrm{d}_{\mathrm{XRD}}$ and thus suggesting primarily monocrystalline particles. The $\mathrm{d}_{\text {TEM }}$ also falls within the targeted optimal range of SPION particle size $(12-20 \mathrm{~nm})$ for high heating rates. ${ }^{28-30}$ The geometric standard deviation $\left(\sigma_{\mathrm{g}}\right)$ was 1.48 and 1.52 for $\mathrm{Zn}_{0.5} \mathrm{Fe}_{2.5} \mathrm{O}_{4}$ and $\mathrm{Mn}_{0.5} \mathrm{Fe}_{2.5} \mathrm{O}_{4}$, respectively, and thus corresponds to the theoretical self-preserving size distribution that is typically attained during flame synthesis. ${ }^{39}$
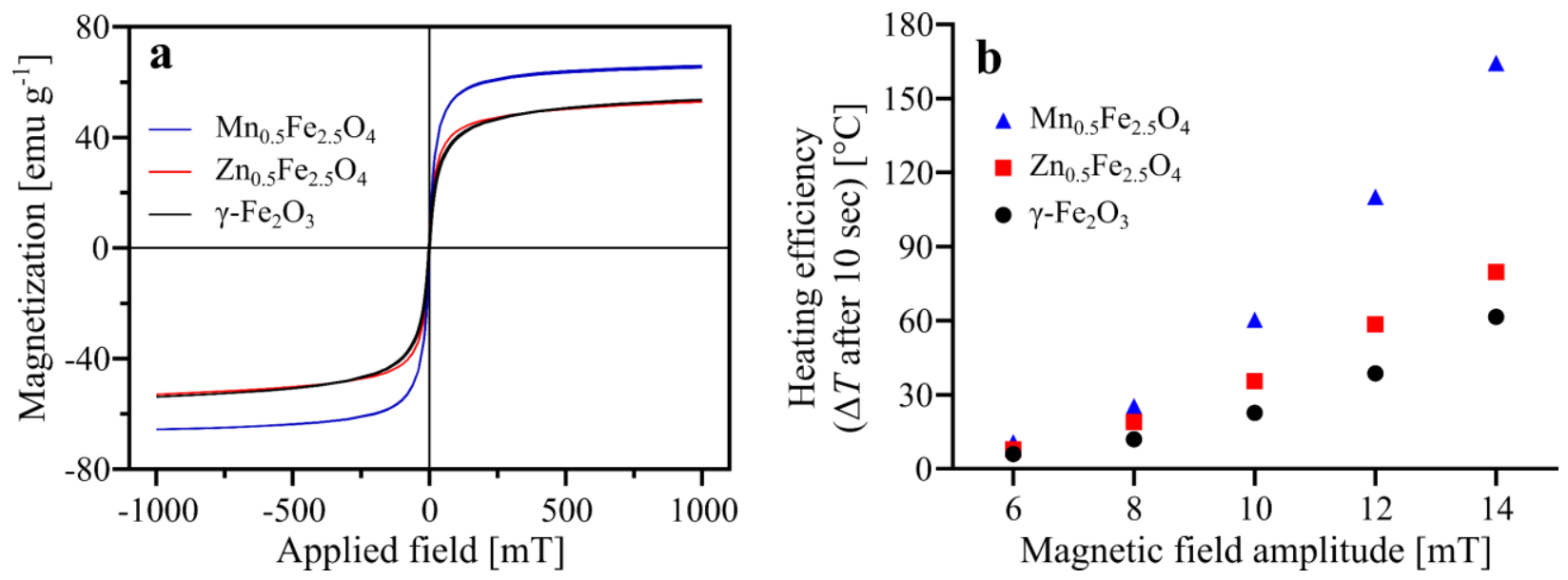

Figure 3. a) Magnetization curves at $300 \mathrm{~K}$ for SPIONs $\left(\gamma-\mathrm{Fe}_{2} \mathrm{O}_{3}\right.$ : black, $\mathrm{Zn}_{0.5} \mathrm{Fe}_{2.5} \mathrm{O}_{4}$ : red and $\mathrm{Mn}_{0.5} \mathrm{Fe}_{2.5} \mathrm{O}_{4}$ : blue). b) Heating efficiency of the SPION powders at $588 \mathrm{kHz}$ and different magnetic field amplitudes for $\gamma-\mathrm{Fe}_{2} \mathrm{O}_{3}$ (black circles), $\mathrm{Zn}_{0.5} \mathrm{Fe}_{2.5} \mathrm{O}_{4}$ (red squares) and $\mathrm{Mn}_{0.5} \mathrm{Fe}_{2.5} \mathrm{O}_{4}$ (blue triangles).

Magnetic Properties and Heating Efficiency. Figure 3a shows the magnetization of flamemade SPIONs. The nanoparticles exhibit nearly zero hysteresis confirming their superparamagnetism. At the maximum field of $1000 \mathrm{mT}$, nearly all particles reached their saturation magnetization. Bulk maghemite has a saturation magnetization of $80 \mathrm{emu} \mathrm{g}^{-1}$, which is 
considerably higher than the $53.7 \mathrm{emu} \mathrm{g}^{-1}$ measured for $\gamma-\mathrm{Fe}_{2} \mathrm{O}_{3}$ here (Table S1). This can be attributed to the small particle size that increases the thickness of the surface spin disordered layer, also called the "magnetically dead layer". $\mathrm{Mn}_{0.5} \mathrm{Fe}_{2.5} \mathrm{O}_{4}$ exhibits the highest saturation magnetization $\left(66.7 \mathrm{emu} \mathrm{g}^{-1}\right)$ of the flame-made SPIONs here, in agreement with the literature. ${ }^{33}$ The dopant occupies the tetrahedral or octahedral sites in the structure of $\gamma-\mathrm{Fe}_{2} \mathrm{O}_{3}$, which affects the magnetocrystalline anisotropy and increases the overall magnetic moment of the unit cell, thereby also affecting the saturation magnetization of the SPIONs. ${ }^{22,32,40}$ Surprisingly, the incorporation of $\mathrm{Zn}^{2+}$ in $\gamma-\mathrm{Fe}_{2} \mathrm{O}_{3}$ did not enhance the saturation magnetization in contrast to previous reports. ${ }^{32,41}$ This could be due to the smaller size of the zinc ferrite compared to manganese ferrite and hence the increased relative volume contribution of the magnetically dead layer to the total particle volume for the former. Moreover, the high substitution of $\mathrm{Fe}^{3+}$ ions by $\mathrm{Zn}^{2+}$ ions at the tetrahedral site also weakens the exchange coupling between the tetrahedral and octahedral sites, thus decreasing the total magnetic moment of the unit cell. ${ }^{41}$

Figure $3 \mathrm{~b}$ shows the heating efficiency (represented as the temperature increase $\Delta T$ after 10 seconds) of the nanoparticle powders in an AMF. The heating efficiency was directly measured on the bulk powders (in contrast to how particle suspensions are typically measured) as they were used here in their dry state in the final tablet formulations, hence the heat dissipation is primarily originating from Néel relaxation of the SPIONs. The zinc, and especially the manganese ferrite, both generated significantly higher temperatures than $\gamma-\mathrm{Fe}_{2} \mathrm{O}_{3}$, in agreement with previous reports. ${ }^{22,23}$ Heating efficiency of SPIONs is often correlated with the saturation magnetization, ${ }^{32}$ and this was especially obvious for $\mathrm{Mn}_{0.5} \mathrm{Fe}_{2.5} \mathrm{O}_{4}$ (Figure 3a). Furthermore, the heating efficiency increased with increasing magnetic field amplitude, also in agreement with previous studies. ${ }^{32,42}$ Overall, these results demonstrate the superior heating efficiency of $\mathrm{Zn}$ and Mn ferrites compared 
to $\gamma-\mathrm{Fe}_{2} \mathrm{O}_{3}$. We therefore investigated these two ferrites further for the magnetic hyperthermia-induced in situ amorphization.

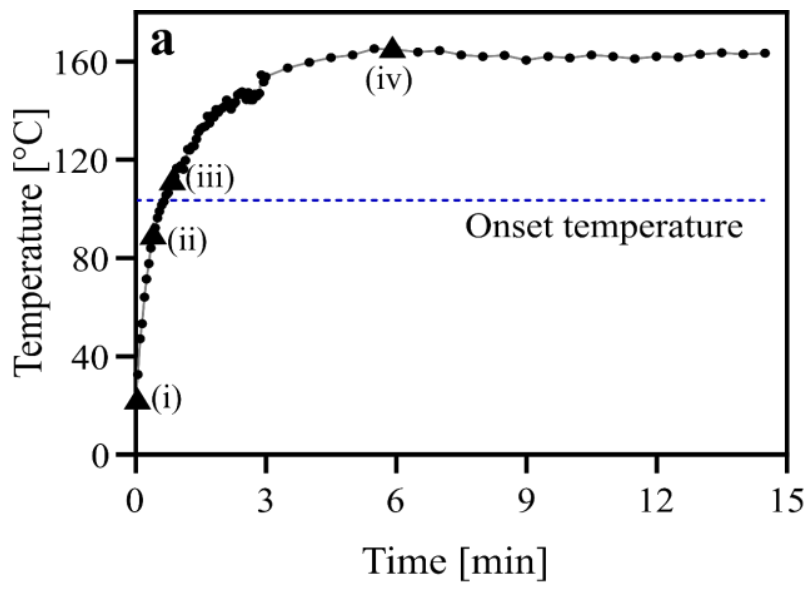

b

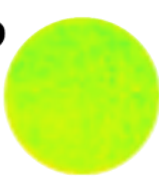

(i)

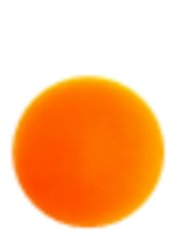

(iii)

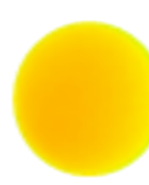

(ii)

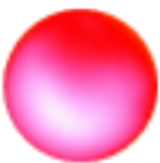

(iv)
Temperature $\left[{ }^{\circ} \mathrm{C}\right]$

165

130

95

60

25
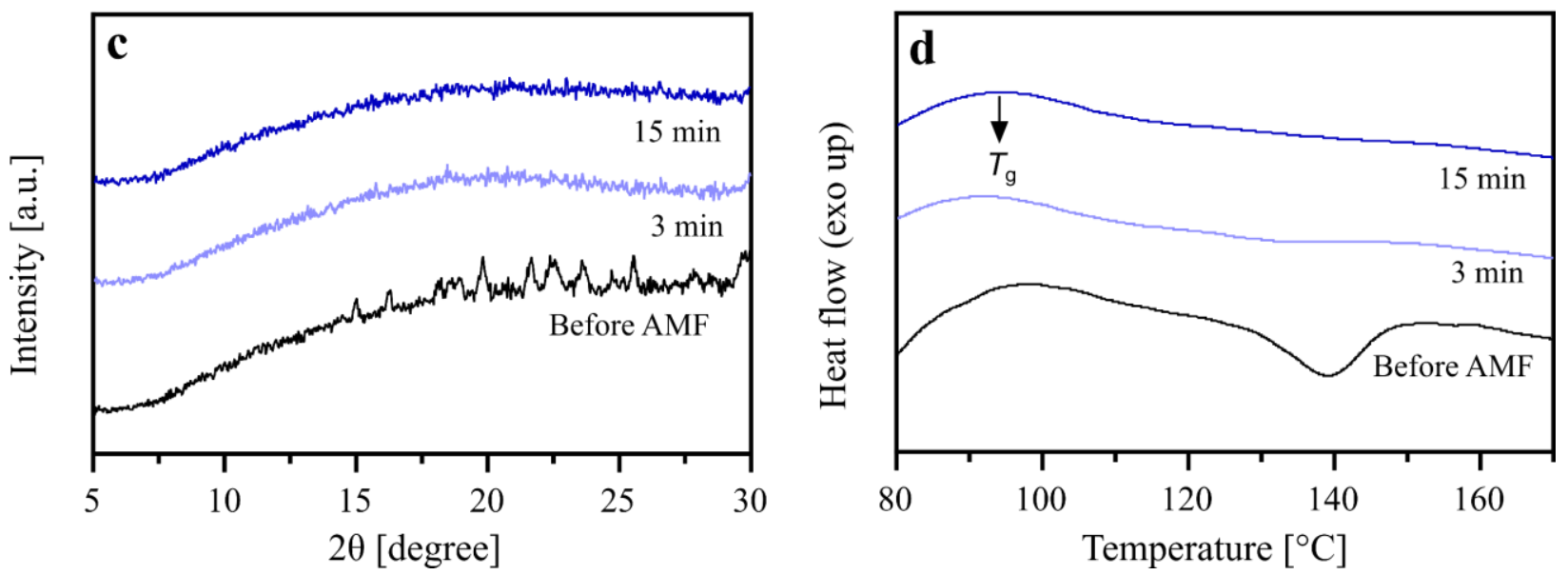

Figure 4. a) Tablet temperature as a function of AMF exposure time for a tablet containing $30 \mathrm{wt} \%$ celecoxib and $20 \mathrm{wt} \% \mathrm{Mn}_{0.5} \mathrm{Fe}_{2.5} \mathrm{O}_{4}$ (tablet 26, Table S3). b) IR images captured at four time points (i: $0 \mathrm{~min}$, ii: $0.5 \mathrm{~min}$, iii: $1 \mathrm{~min}$, iv: $6 \mathrm{~min}$ ). The color scale indicates the temperature of the tablet. c) XRD diffractograms and d) DSC thermograms of tablets containing $30 \mathrm{wt} \%$ celecoxib and $20 \mathrm{wt} \% \mathrm{Mn}_{0.5} \mathrm{Fe}_{2.5} \mathrm{O}_{4}$ before and after 3 and 15 minutes of $\mathrm{AMF}$ exposure time.

Magnetic Hyperthermia-Induced In Situ Drug Amorphization in Tablets. Tablets were prepared based on the formulation design space (Table S2) constructed using DoE to investigate factors for magnetic hyperthermia-induced drug amorphization. Table S3 summarizes the tablet 
compositions, process conditions and the observed degree of amorphization. The tablet containing $30 \mathrm{wt} \%$ celecoxib and $20 \mathrm{wt} \% \mathrm{Mn}_{0.5} \mathrm{Fe}_{2.5} \mathrm{O}_{4}$ exposed to AMF for 15 min (tablet 26, Table S3) showed maximum amorphous content induced by in situ amorphization, and is thus presented here in detail (Figure 4). Figure 4a shows the temperature profile of this tablet and the thermal images recorded with IR camera at four time points are shown in Figure $4 \mathrm{~b}$. The tablet surface temperature rapidly increased from room temperature to $154^{\circ} \mathrm{C}$ within the first three minutes of AMF exposure. The tablet temperature further increased to a maximum $\left(T_{\max }\right)$ of $165{ }^{\circ} \mathrm{C}$ after 6 minutes and was maintained there for the remaining time of AMF exposure. As the SPIONs are homogenously distributed in the matrix, hyperthermia results in uniform heating of the entire tablet, as shown here by the mono-colored thermal images (Figure 4b). The uniform heating ensures complete drug amorphization in the tablets. This is a clear advantage of magnetic hyperthermia-induced amorphization over the previously reported laser-radiation approach. The latter can only be applied to thin tablets due to the limited penetration depth of the laser. ${ }^{8}$

Some of the tablets showed deformation after AMF exposure due to water evaporation and increased polymer mobility above the $T_{\mathrm{g}}$ of PVP (here $T_{\mathrm{g}}=80-85^{\circ} \mathrm{C}$ ). A significant decrease in viscosity of the polymer has been observed at approximately $15-25^{\circ} \mathrm{C}$ above the $T_{\mathrm{g}}$ of the polymer, ${ }^{43,44}$ enabling the drug dissolution and amorphization process. Here, the onset temperature for drug amorphization was determined by differential scanning calorimetry (DSC) and was found to be $103.6,117.7$, and $117.6{ }^{\circ} \mathrm{C}$ for a drug load of 30,40 , and $50 \mathrm{wt} \%$ respectively $\left(T_{\mathrm{g}}+\right.$ (15-25) ${ }^{\circ} \mathrm{C}$ depending on $\mathrm{wt} \%$ of celecoxib). At temperatures $>T_{\mathrm{g}}$, the polymer viscosity decreases leading to a drastic increase of molecular mobility in the network. Thus, the drug dissolves easily into the polymer ${ }^{43}$ and in situ amorphization is initiated. The AMF-exposed tablet in Figure 4a significantly exceeded the onset temperature required for amorphization of celecoxib and was 
maintained above that temperature for an adequate time, thus ensuring an efficient in situ amorphization by hyperthermia.

The degree of amorphization after AMF exposure of the tablets was quantified by XRD and DSC. Figure 4c shows the XRD diffractograms of tablet 26 as prepared and after 3 and 15 minutes of AMF exposure. The as prepared tablet displays the characteristic diffraction peaks of crystalline celecoxib. The intensity of the crystalline peaks diminished already after three minutes of AMF exposure. Complete amorphization was achieved after 15 minutes, as indicated by the "halo" characteristic of an amorphous material. Similarly, the depressed melting endotherm of crystalline celecoxib in the presence of PVP at about $140^{\circ} \mathrm{C}$ in the as-prepared tablets was no longer detected by DSC after AMF exposure (Figure 4d). The successful amorphization is evident in the DSC thermograms from a single glass transition $\left(T_{\mathrm{g}}\right)$ of the polymer after in situ amorphization (Figure 4d).

\section{Modelling of the Maximum Tablet Temperature and Degree of Drug Amorphization. A} multiple linear regression model (Table 1) was generated from the tablet data (Table S3) to investigate the effects of process parameters on drug amorphization. Response modeling resulted in high $\mathrm{R}^{2}$ and $\mathrm{Q}^{2}$ values for degree of drug amorphization $\left(\mathrm{R}^{2}=0.917, \mathrm{Q}^{2}=0.842\right)$ and $T_{\max }\left(\mathrm{R}^{2}\right.$ $\left.=0.906, \mathrm{Q}^{2}=0.865\right)$. Moreover, the predicted and observed values showed strong correlation (Figure S2). It should be noted that an experiment outside the action limit of \pm 4 standard deviations was identified as an outlier based on the deleted studentized residuals, and removed from the final regression model. 
Table 1. Adjusted models for degree of drug amorphization and maximum tablet temperature $\left(T_{\max }\right)$.

\begin{tabular}{|c|c|c|c|c|}
\hline \multirow[t]{2}{*}{ Model terms } & \multicolumn{2}{|c|}{ Degree of drug amorphization } & \multicolumn{2}{|c|}{$T_{\max }$} \\
\hline & Coefficient & $p$-value & Coefficient & $p$-value \\
\hline Composition $\left(\mathrm{Mn}_{0.5} \mathrm{Fe}_{2.5} \mathrm{O}_{4}\right)$ & $21.2630^{\text {a) }}$ & $\leq 0.0001^{\text {a) }}$ & 19.4226 & $\leq 0.0001$ \\
\hline Composition $\left(\mathrm{Zn}_{0.5} \mathrm{Fe}_{2.5} \mathrm{O}_{4}\right)$ & $-21.2630^{a)}$ & $\leq 0.0001^{\mathrm{a})}$ & -19.4226 & $\leq 0.0001$ \\
\hline SPION content & 20.1269 & $\leq 0.0001$ & $22.2300^{a)}$ & $\leq \mathbf{0 . 0 0 0 1}{ }^{\text {a) }}$ \\
\hline Drug load & -6.1089 & $\leq 0.01$ & - & - \\
\hline AMF time & $2.4589^{\mathrm{b})}$ & $0.2808^{\mathrm{b})}$ & $2.9284^{\mathrm{b})}$ & $0.1788^{\mathrm{b})}$ \\
\hline AMF time * AMF time & $-5.3351^{\mathrm{b})}$ & $0.1313^{\mathrm{b})}$ & - & - \\
\hline SPION content $*$ Composition & 8.7303 & $\leq 0.001$ & 5.2400 & $\leq 0.05$ \\
\hline SPION content $*$ AMF time & $4.5143^{\mathrm{b})}$ & $0.0744^{\mathrm{b})}$ & & \\
\hline
\end{tabular}

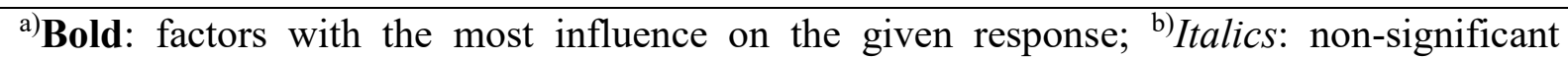
parameters retained to conserve either the hierarchy or the predictability of the model.

SPION content in the tablets had the strongest positive influence on tablet temperature (Table 1). For all experiments, tablet temperature initially increased rapidly with exposure time until it plateaued (Table S3) and $T_{\max }$ was then maintained until the end of AMF exposure, which is also shown in tablet 26 (Figure 4a). Mn ferrites showed a much stronger influence on tablet temperature than $\mathrm{Zn}$ ferrites. Furthermore, $T_{\max }$ showed a strong linear relationship to the extent of celecoxib amorphization $(\mathrm{r}=0.96)$. 


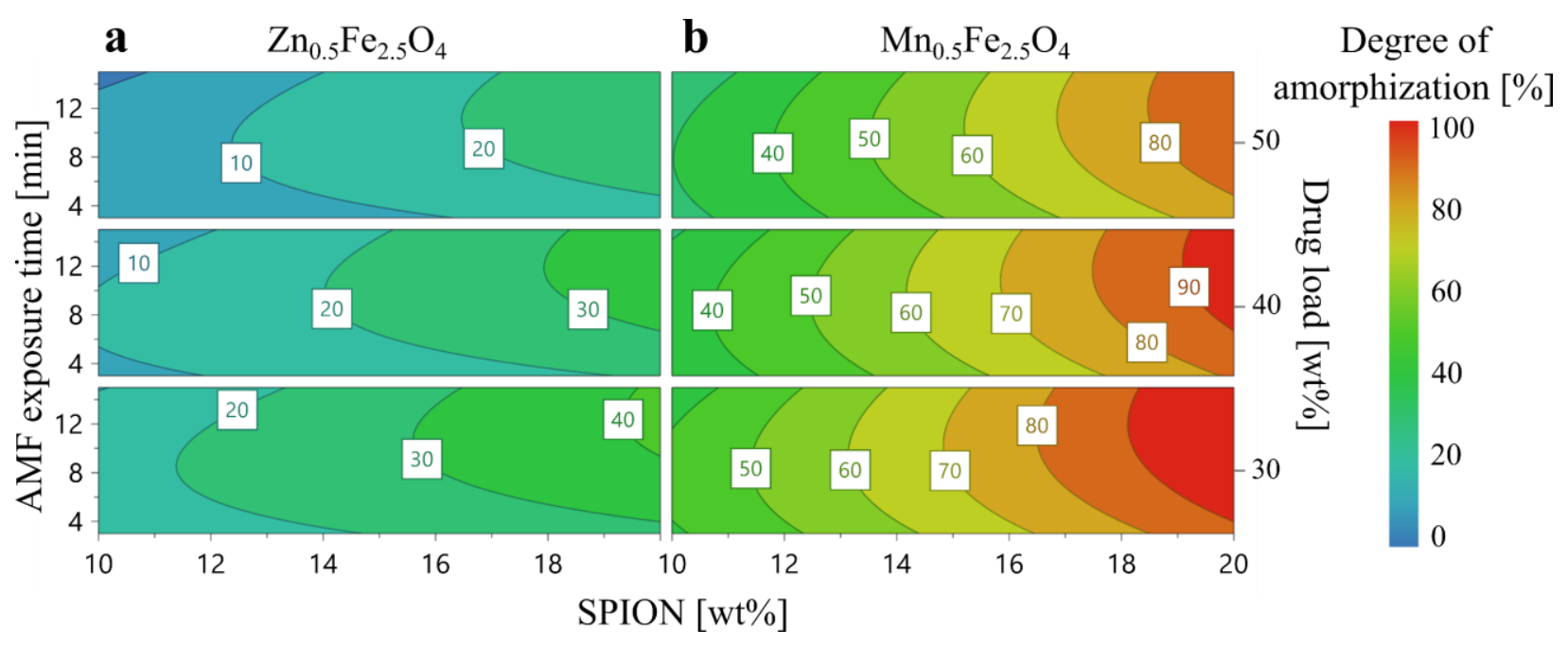

Figure 5. Contour plots showing the degree of celecoxib amorphization for tablets containing $\mathrm{Zn}_{0.5} \mathrm{Fe}_{2.5} \mathrm{O}_{4}$ (a) and $\mathrm{Mn}_{0.5} \mathrm{Fe}_{2.5} \mathrm{O}_{4}$ (b) as a function of AMF exposure time, SPION content and drug load. The color scale indicates the degree of celecoxib amorphization as measured by DSC.

SPION composition had the strongest influence on the degree of drug amorphization (Table 1). The contour plots for $\mathrm{Zn}_{0.5} \mathrm{Fe}_{2.5} \mathrm{O}_{4}$ and $\mathrm{Mn}_{0.5} \mathrm{Fe}_{2.5} \mathrm{O}_{4}$ (Figure 5) show the extent of drug amorphization as a function of AMF exposure time, drug load and SPION content. Red areas in the contour plot illustrate process conditions that achieved $>90 \%$ degree of amorphization. $\mathrm{Mn}_{0.5} \mathrm{Fe}_{2.5} \mathrm{O}_{4}$ was more effective than $\mathrm{Zn}_{0.5} \mathrm{Fe}_{2.5} \mathrm{O}_{4}$ in formation of completely amorphous ASDs. This can be attributed to the better heating efficiency of $\mathrm{Mn}_{0.5} \mathrm{Fe}_{2.5} \mathrm{O}_{4}$ (Figure 3b), resulting in higher tablet temperatures and faster dissolution of celecoxib into the PVP network. The SPION content also positively affected the degree of drug amorphization with no significant quadratic term, indicating a linear effect of this parameter in the entire design space. However, the SPION content showed a significant interaction term with the SPION composition. In contrast, the tablet drug load had a negative influence on drug amorphization.

Thus, the tablets with $50 \mathrm{wt} \%$ drug load showed a lower degree of amorphization compared to $30 \mathrm{wt} \%$ at similar exposure times and temperatures. This follows the Noyes-Whitney equation ${ }^{45}$ 
that predicts that for a higher drug load, a higher $T_{\max }$ can result in complete dissolution in a solvent, here the polymer. Higher temperatures increase the saturation solubility of the drug in the polymer, lower the viscosity of the continuous (polymer) phase, and increase the diffusion coefficient according to the Stokes-Einstein equation. This in turn results in a faster dissolution rate. In fact, for tablets 27 and 28 with a high SPION concentration of $20 \mathrm{wt} \%$ (Table S3), celecoxib was not completely amorphized, even though temperatures reached above the onset temperature of dissolution. This could have been a result of the high drug load $(50 \mathrm{wt} \%)$ that might require longer exposure times ( $>15$ minutes) than applied here to result in complete drug amorphization, since dissolution is a time and temperature dependent process. It should be noted that at high drug loads, the drug becomes the bulk of the tablet, resulting in incomplete dissolution of the drug into the polymer also due to insufficient polymer content.

The AMF exposure time was not a significant factor for drug amorphization in the selected design space; however, the model term for the duration of AMF was retained to improve the predictability of the model. The contour plot for tablets containing Zn ferrite (Figure 5a) indicate that the tablets that failed to reach the onset temperature (Table S3) show minimal amorphization despite prolonged AMF exposure. Thus, a minimum AMF exposure time of three minutes was selected to ensure at least some degree of drug amorphization. As a result, the AMF exposure time is a non-significant factor in the current model. In future studies, the effect of time on hyperthermia-induced drug amorphization could be investigated by increasing the range and interval of the design. As previously discussed, heating efficiency of SPIONs depends strongly on the operating AMF amplitude. The maximum AMF amplitude used in this study was confined due to the instrument limitations, however using higher AMF amplitude could potentially decrease the 
time required for AMF exposure and the SPION content required to achieve complete amorphization.

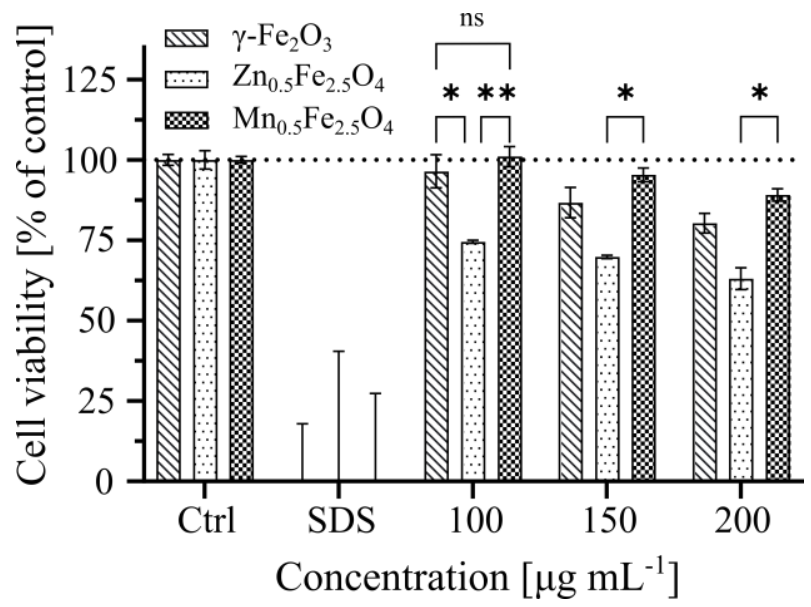

Figure 6. Cell viability of non-differentiated Caco-2 cells after exposure to $\gamma-\mathrm{Fe}_{2} \mathrm{O}_{3}, \mathrm{Zn}_{0.5} \mathrm{Fe}_{2.5} \mathrm{O}_{4}$ and $\mathrm{Mn}_{0.5} \mathrm{Fe}_{2.5} \mathrm{O}_{4}$ at different particle concentrations $\left(100,150\right.$, and $\left.200 \mu \mathrm{g} \mathrm{mL}{ }^{-1}\right)$ for 24 hours. Cell viability was determined using the CellTiter-Glo Luminescent Cell Viability Assay and calculated as a percentage of the control (set to 100\%). A positive control (SDS: sodium dodecyl sulfate) is also shown. All data are expressed as mean \pm SD. $p<0.1234$ (ns), $0.0332(*), 0.0021$ $(* *), 0.0002(* * *)$, and $0.0001(* * * *)$.

Nanoparticle Cytotoxicity on Caco-2 Cells. The most effective hyperthermia-induced drug amorphization was achieved using the $\mathrm{Mn}_{0.5} \mathrm{Fe}_{2.5} \mathrm{O}_{4}$ nanoparticles (Figure $5 \mathrm{~b}$ ). However, the final choice of an enabling excipient for in situ drug amorphization must also be guided by the potential toxicity of the nanomaterial. Figure 6 shows the dose-dependent viability of human intestinal Caco-2 cells following 24 hours of exposure to the SPIONs. Cell viability after nanoparticle exposure is highly dependent on cell line and differentiation state, exposure time and concentration, and physicochemical properties of the nanoparticles. Here, cell viability was assessed using non-differentiated cells, which are more sensitive than differentiated ones. ${ }^{46}$ In other words, our model is highly sensitive compared to the in vivo condition, and better able to 
detect any toxic effects exhibited by the flame-made SPIONs. The cell viability was not affected by $\gamma-\mathrm{Fe}_{2} \mathrm{O}_{3}$ and $\mathrm{Mn}_{0.5} \mathrm{Fe}_{2.5} \mathrm{O}_{4}$ exposure at $100 \mu \mathrm{g} \mathrm{mL}^{-1}$ (corresponding to an oral dose of $25 \mathrm{mg}$ SPIONs ingested with a $250 \mathrm{~mL}$ glass of water) and was only slightly decreased at higher concentrations. This declining trend of cell viability with increasing particle concentration (Figure 6), suggests a dose-dependent toxicity for all particles. The minor adverse effect of iron oxide nanoparticles on Caco-2 cell viability has also previously been reported. ${ }^{47}$ In contrast, $\mathrm{Zn}_{0.5} \mathrm{Fe}_{2.5} \mathrm{O}_{4}$ dramatically reduced cell viability to $75 \%$ compared to the control already after exposure to $100 \mu \mathrm{g} \mathrm{mL} L^{-1}$ and further to $63 \%$ at $200 \mu \mathrm{g} \mathrm{mL} L^{-1}$. $\mathrm{Mn}_{0.5} \mathrm{Fe}_{2.5} \mathrm{O}_{4}$ on the other hand shows significantly higher cell viability than zinc ferrite. Previous studies have also reported relatively higher cytotoxicity of zinc ferrite compared to manganese ferrite, which can be attributed to the oxidative stress induced by generation of reactive oxygen species by the former. ${ }^{22,48}$ Overall, the high heating efficiency and low cytotoxicity of the $\mathrm{Mn}_{0.5} \mathrm{Fe}_{2.5} \mathrm{O}_{4}$ nanoparticles suggest they are efficient as enabling excipients for hyperthermia-induced in situ amorphization.

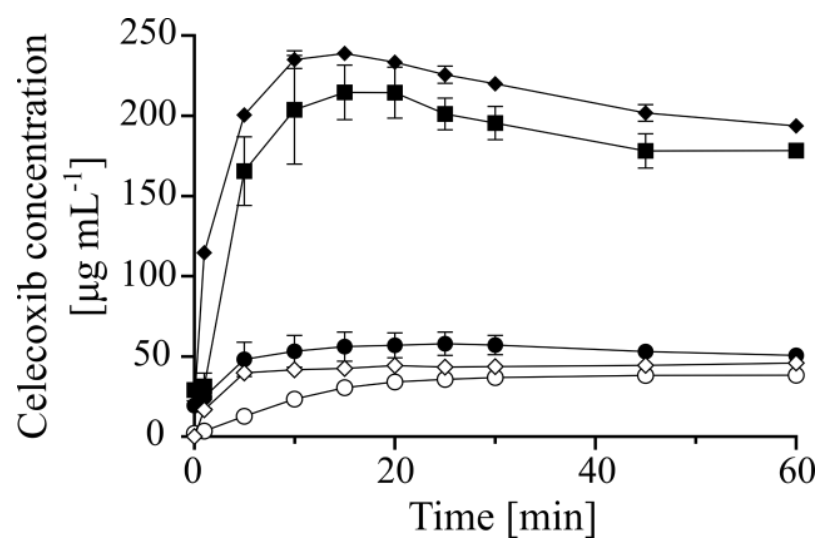

Figure 7. In vitro dissolution profiles of tablets at a dose corresponding to $400 \mu \mathrm{g} \mathrm{mL}^{-1}$ of celecoxib in fasted state simulated intestinal fluid (FaSSIF). Crystalline celecoxib (open circles); amorphous celecoxib (filled circles); conventional amorphous solid dispersion of celecoxib (30 wt $\%$ ) in PVP (filled squares); tablet containing $\mathrm{Mn}_{0.5} \mathrm{Fe}_{2.5} \mathrm{O}_{4}(20 \mathrm{wt} \%$ ) and celecoxib (30 wt $\%$ ) in PVP before AMF exposure (open diamonds), and after AMF exposure of 15 min (filled 
diamonds). Values represent mean celecoxib concentrations $\pm \mathrm{SD}, n=3$ ( $n=2$ for tablet containing Mn ferrites after AMF exposure).

In Vitro Dissolution Studies. In vitro dissolution assays of celecoxib ASDs in biorelevant intestinal media under non-sink conditions have previously shown good correlation with their in vivo performance. ${ }^{49} \mathrm{We}$ therefore used them to benchmark the in situ amorphized ASD. Figure 7 shows the in vitro dissolution profiles of crystalline celecoxib, amorphous celecoxib, conventional ASD (prepared by melt quenching) and tablets containing $\mathrm{Mn}_{0.5} \mathrm{Fe}_{2.5} \mathrm{O}_{4}$, before and after magnetic hyperthermia-induced amorphization. The conventional ASD showed a considerably higher dissolution rate and maximum drug concentration $\left(C_{\max }\right)$ than pure crystalline or amorphous celecoxib. This is in good agreement with previous studies demonstrating the superior dissolution characteristics of ASDs compared to pure compounds. ${ }^{50}$ The dissolution profile of ASDs are mainly controlled by generation and stabilization of a supersaturated solution, ${ }^{51}$ this is commonly referred to as the 'spring and parachute effect', and suggests that the performance of an ASD is governed by the dissolution rate and crystallization inhibition of the polymer. PVP maintains the balance between the dissolution rate enhancement and precipitation inhibition. The tablets containing Mn ferrites achieved a similar dissolution profile after AMF exposure as the conventional ASD, reaching a $C_{\max }$ of $239 \mu \mathrm{g} \mathrm{mL}^{-1}$ in $15 \mathrm{~min}$. This concentration was significantly higher than $C_{\max }$ of conventional ASD $\left(215 \mu \mathrm{g} \mathrm{mL}^{-1}\right)$ and approximately five times higher than the $C_{\max }$ of the SPION-containing tablets before AMF exposure $\left(46 \mu \mathrm{g} \mathrm{m}^{-1}\right)$. At the end of sampling period (6 hours), the AMF-exposed tablets maintained a higher solubility compared to the conventional ASD and the crystalline celecoxib (Figure S4). The presence of crystalline nanoparticles in the formulation could act as a crystalline nuclei and trigger re-crystallization, however Mn ferrites did not trigger re-crystallization, thus further affirming their suitability as an 
in situ amorphization enabling excipient. Overall, this confirms that the novel magnetic hyperthermia-induced amorphization produces ASDs with the same performance as conventional ASDs in terms of their dissolution behavior.

\section{CONCLUSIONS}

This work demonstrates the ability of SPIONs to induce in situ amorphization in tablets intended for oral administration. Upon exposure to an AMF, elevated temperatures were achieved in SPION-containing tablets, leading to high amorphization and improved in vitro dissolution. The degree of amorphization was strongly linked to the maximum tablet temperature, which depended significantly on the SPION composition, SPION content and the drug load. Complete amorphization and high apparent solubility were achieved in tablets with $20 \mathrm{wt} \% \mathrm{Mn}_{0.5} \mathrm{Fe}_{2.5} \mathrm{O}_{4}$ and $30 \mathrm{wt} \%$ celecoxib after 15 minutes of AMF exposure. Furthermore, unlike laser and microwaveinduced amorphization, these tablets are homogenously exposed to the AMF and use safer excipients that are less likely to cause drug degradation. The in situ amorphization can be finetuned according to the obtained DoE model and the method can be widely applied to ASDs with other polymer-drug compositions. The use of a biocompatible excipient produced by a scalable synthesis technique, along with the high drug load in ASDs produced by in situ amorphization, make the developed method a promising tool for broader use of ASDs as enabling formulations in oral drug delivery.

\section{EXPERIMENTAL SECTION}

Particle synthesis. Zinc and manganese ferrites $\left(\mathrm{Zn}_{0.5} \mathrm{Fe}_{2.5} \mathrm{O}_{4}\right.$ and $\left.\mathrm{Mn}_{0.5} \mathrm{Fe}_{2.5} \mathrm{O}_{4}\right)$ were synthesized by FSP. ${ }^{27}$ Liquid precursor solutions were prepared by dissolving iron (III) nitrate 
nonahydrate (purity 98\%; Sigma-Aldrich, Sweden) and either zinc nitrate hexahydrate (purity 98\%; Sigma- Aldrich) or manganese (II) nitrate tetrahydrate (purity 97\%; Sigma-Aldrich) in a solvent mixture (1:1) of 2-ethylhexanoic acid (99\%; Sigma-Aldrich) and ethanol (>99.7\%, HPLC grade; VWR, Belgium) to get a total metal concentration of $0.7 \mathrm{M}$. Reference pure iron oxide ( $\gamma$ $\mathrm{Fe}_{2} \mathrm{O}_{3}$ ) was produced from a $0.7 \mathrm{M}$ iron (III) nitrate nonahydrate precursor solution.

The precursor solutions were stirred for at least 1 hour at room temperature. Subsequently, the precursor was fed at $6 \mathrm{~mL} \mathrm{~min}^{-1}$ and dispersed using $3 \mathrm{~L} \mathrm{~min}^{-1} \mathrm{O}_{2}(>99.5 \%$, Linde AGA Gas AB, Sweden) at constant pressure (1.6 bar). The flame was ignited by a premixed supporting flame of $\mathrm{CH}_{4}$ and $\mathrm{O}_{2}\left(>99.5 \%\right.$, Linde $\mathrm{AGA}$ Gas $\mathrm{AB}$ ) at flow rates of $1.5 \mathrm{~L} \mathrm{~min}^{-1}$ and $3.2 \mathrm{~L} \mathrm{~min}^{-1}$, respectively. A $5 \mathrm{~L} \mathrm{~min}^{-1} \mathrm{O} 2$ sheath gas was fed through the outermost sinter metal plate of the FSP burner. Gas flow rates were controlled with calibrated mass flow controllers (Bronkhorst, the Netherlands). The particles were collected on a glass fiber filter (Albert LabScience, Germany) with the aid of a Mink MM 1144 BV vacuum pump (Busch, Sweden).

Particle Characterization. The specific surface area was determined by nitrogen adsorption (Brunauer-Emmett-Teller; BET method) at $77 \mathrm{~K}$ using a Tristar II Plus (Micromeritics, USA) after degassing for at least 3 hours at $110^{\circ} \mathrm{C}$ under a flow of nitrogen gas. X-ray diffraction (XRD) patterns were obtained at ambient temperature with a MiniFlex X-ray diffractometer (Rigaku Europe, Germany) using $\mathrm{Cu} \mathrm{K} \alpha 1$ radiation (1.5406 $\AA$ ) and at $40 \mathrm{kV}$ and $15 \mathrm{~mA}$. The patterns were recorded between $10^{\circ}$ and $80^{\circ} 2 \theta$ at a step size of $0.01^{\circ} 2 \theta$ and a scan speed of $2.00 \mathrm{deg} \min ^{-1}$. A DTex detector was used in narrow energy gap mode to suppress iron fluorescence background from the copper radiation. XRD data were analyzed using PDXL2 software (Rigaku Europe, Germany). All patterns were normalized relative to the intensity of the peak corresponding to the (311) crystal plane. The average crystal size ( $\left.\mathrm{d}_{\mathrm{XRD}}\right)$ of SPIONs was calculated by Rietveld 
refinement analysis using the PDXL2 software. Particle morphology was visualized by transmission electron microscopy (TEM) with Tecnai ${ }^{\mathrm{TM}}$ G2 Spirit BioTwin, (Thermo Fisher/FEI, USA) operating at $80 \mathrm{kV}$. The samples were suspended in $99.5 \%$ ethanol and deposited (as a $5 \mu \mathrm{L}$ drop) on a 200-mesh copper grid (Ted Pella, USA) coated with formvar and carbon. The primary particle size distribution was measured by counting 360 and 394 particles of $\mathrm{Zn}_{0.5} \mathrm{Fe}_{2.5} \mathrm{O}_{4}$ and $\mathrm{Mn}_{0.5} \mathrm{Fe}_{2.5} \mathrm{O}_{4}$, respectively, using ImageJ software. The particle magnetization was recorded on a vibrating sample magnetometer (Lake Shore, USA) and a Physical Property Measurement System (Quantum Design, USA). Magnetization versus magnetic field was measured in the field range $\pm 1000 \mathrm{mT}$ at a constant temperature of $25^{\circ} \mathrm{C}$. The thermal dissipation of nanoparticle powders was measured using an oscillating magnetic field apparatus (Magnetherm; NanoTherics Ltd., UK). The heat dissipation from the bulk powders was measured with a fiber optic probe. Approximately $25 \mathrm{mg}$ of each SPION powder was transferred to a $2 \mathrm{~mL}$ glass vial and placed inside a coil with nine windings. The nominal oscillation frequency was set to $588.5 \mathrm{kHz}$ and the magnetic field strength to $14 \mathrm{mT}$. The heating efficiency was calculated as the rise in temperature in the initial 10 seconds.

Cell viability assay was performed to assess the cytotoxicity of SPIONs. Cell culture media and reagents were purchased from Thermo Fisher Scientific (USA) or Sigma-Aldrich (USA). Caco-2 cells (originally obtained from the American Type Culture Collection), passage 95-105, were maintained in Dulbecco's modified Eagle's medium, containing 10\% (v/v) fetal bovine serum and $1 \%(\mathrm{v} / \mathrm{v})$ nonessential amino acids. The cells were cultured in a humidified incubator (at $37^{\circ} \mathrm{C}$, $10 \% \mathrm{CO} 2$ ) in $75 \mathrm{~cm}^{2}$ tissue culture flasks. Stock suspensions of the SPIONs in Milli Q water were prepared at $10 \mathrm{mg} \mathrm{mL}^{-1}$ for $\gamma-\mathrm{Fe}_{2} \mathrm{O}_{3}$ and $\mathrm{Mn}_{0.5} \mathrm{Fe}_{2.5} \mathrm{O}_{4}$ and at $2 \mathrm{mg} \mathrm{mL}^{-1}$ for $\mathrm{Zn}_{0.5} \mathrm{Fe}_{2.5} \mathrm{O}_{4}$. The suspensions were prepared with a cup horn ultrasonicator (Sonics, USA) until no change in 
hydrodynamic diameter was observed. The hydrodynamic diameter was measured by dynamic light scattering (Litesizer 500, AntonPaar, Austria). The stock suspensions were diluted further with cell culture medium to achieve concentrations of SPIONs at 100, 150, and $200 \mu \mathrm{gL}^{-1}$. Caco-2 cells were plated into black opaque 96-well plates at a density of $5 \times 104$ cells per well in $300 \mu \mathrm{L}$ of culture medium. The cells were allowed to attach for 24 hours before treatment. Subsequently, culture medium was replaced by $100 \mu \mathrm{L}$ particle suspensions in six replicates per treatment and incubated for 24 hours (at $37^{\circ} \mathrm{C}, 10 \% \mathrm{CO}_{2}$ ). Positive controls were prepared by diluting $10 \%(\mathrm{w} / \mathrm{v})$ sodium dodecyl sulfate (SDS) in water to achieve a final concentration of $0.22 \%(\mathrm{v} / \mathrm{v})$ SDS in the cell culture medium. Culture medium was used as negative control. The water content in all treatments was kept at or below $2 \%$. Finally, the viability of Caco-2 cells was evaluated with the CellTiter-Glo Luminescent Cell Viability Assay (Promega, USA). The luminescent signal from each well was determined with a plate reader (Tecan, Switzerland). A two-way analysis of variance (ANOVA) using Tukey's multiple comparisons test was used to compare the groups. Data analysis was performed using GraphPad Prism 9.0 software (La Jolla, CA, USA). $p$ values were calculated as $0.1234(\mathrm{~ns}), 0.0332(*), 0.0021(* *), 0.0002(* * *)$, and $<0.0001(* * * *)$.

Tablet preparation and hyperthermia-induced drug amorphization. A DoE approach with a D-optimal design, resembling two, parallel central composite face (CCF; Figure S3)-centered fractional factorial designs, was used to study the effect of critical process parameters and their interactions on the $T_{\max }$ and the degree of drug amorphization in the tablets. The experiment was set up using MODDE 12.1 (Umetrics AB, Sweden). The nanoparticle load was varied at 10, 15, and $20 \mathrm{wt} \%$ (with respect to the total tablet weight, Table S2) and the celecoxib load at 30, 40, and $50 \mathrm{wt} \%$ (with respect to the polymer weight, Table S2). Two SPIONs $\left(\mathrm{Zn}_{0.5} \mathrm{Fe}_{2.5} \mathrm{O}_{4}\right.$ and 
$\left.\mathrm{Mn}_{0.5} \mathrm{Fe}_{2.5} \mathrm{O}_{4}\right)$ and the duration of AMF exposure (3-15 min) were also included in the design. In total, 34 experiments were conducted (Table S3), of which each CCF design had eight full factorial points, three center points and six star points. Models were fitted with multiple linear regression and adjusted by removing non-significant model terms. A value of $p<0.05$ was considered significant. The surface contour plot was constructed to visualize the effect of the factors on tablet temperature and drug amorphization.

The tablets were prepared based on the experimental design. Physical mixtures of SPIONs, celecoxib $\left(M_{\mathrm{w}}=381.4 \mathrm{~g} \mathrm{~mol}^{-1}\right), \operatorname{PVP}\left(M_{\mathrm{w}}=2000-3000 \mathrm{~g} \mathrm{~mol}^{-1}\right)$ and magnesium stearate $(0.5 \mathrm{wt} \%)$ $\left(M_{\mathrm{w}}=591.3 \mathrm{~g} \mathrm{~mol}^{-1}\right)$ were prepared using mortar and pestle. Celecoxib and magnesium stearate were purchased from Fagron Nordic A/S (Denmark). Kollidon 12PF (PVP) was a kind gift from BASF (Germany). From the physical mixtures, $50 \pm 2 \mathrm{mg}$ flat-faced tablets $(\varnothing 6 \mathrm{~mm}$ ) were prepared using an instrumented single punch tablet press GTP-1 (Gamlen Instruments, UK). The tablet press was fitted with a $500 \mathrm{mg}$ load cell (CT6-500-022) and used at a compression pressure of $160 \mathrm{MPa}$. The tablets and the mixtures were stored in airtight containers until further use.

The tablets were exposed to an alternating magnetic field (AMF) using Magnetherm (Nanotherics Ltd., UK). They were placed on a glass petri dish inside a coil with nine windings and the nominal oscillation frequency was set to $588.5 \mathrm{kHz}$ and the magnetic field intensity at $14 \mathrm{mT}$. The AMF exposure time was varied according to the DoE (Table S3). The increase in tablet surface temperature in the AMF was measured using an IR thermal camera (Fluke Ti480 Pro, Fluke Europe, the Netherlands). A thermal image was taken every third second for the first three minutes, and thereafter every 30 seconds. The IR images were analyzed using SmartView 4.3 (Fluke Europe, the Netherlands). 
Tablet Characterization. Tablets exposed to AMF were gently powderized by a mortar and pestle for subsequent solid-state analysis. The water content of the pure compounds, the physical mixtures and the tablets after AMF exposure was determined with a thermogravimetric analyzer (TGA; Discovery, TA Instruments Ind., USA). The experiments were conducted under a nitrogen gas purge of $25 \mathrm{~mL} \mathrm{~min}-1$ and a heating rate of $10{ }^{\circ} \mathrm{C} \mathrm{min}^{-1}$ from ambient temperature to $170{ }^{\circ} \mathrm{C}$. Each experiment was conducted in duplicate $(n=2)$ for the pure compounds and physical mixtures, and as a single run for the powderized tablets. The weight loss (corresponding to the water content) was determined using the TA Instruments TRIOS software (version 5.1.1). Drug crystallinity of the pure substances, physical mixtures and powderized AMF-exposed tablets was analyzed with an X-Ray powder X'Pert Pro diffractometer (PANalytical, The Netherlands) using $\mathrm{Cu} \mathrm{K} \alpha$ radiation $(\lambda=1.54187 \AA)$. The diffractograms were recorded from $2 \theta 5^{\circ}$ to $30^{\circ}$ at $45 \mathrm{kV}$ and $40 \mathrm{~mA}$. As the superparamagnetic nanoparticles fluoresce, the pulse height distribution level was adjusted to $40-80 \%$ of the energy to compensate for the baseline drift and to obtain a higher signal-to-noise ratio. The diffractograms were analyzed using the X'Pert HighScore Plus software (version 2.2.4).

Differential scanning calorimetry (DSC; Discovery, TA Instruments, USA) scans were collected for the physical mixtures and the AMF-exposed tablets. All experiments were conducted under a

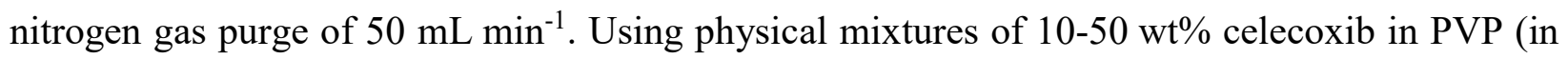
$10 \%$ increments), the melting enthalpy of the depressed melting was determined and fitted with a second degree polynomial function. The calibration experiments were conducted in duplicate $(n=$ 2). 3-5 mg of each sample was weighted in Tzero aluminum pans with hermetic lids. The lid was perforated to allow water evaporation. A modulated DSC (mDSC) run was performed at a heating rate of $3{ }^{\circ} \mathrm{C} \mathrm{min}{ }^{-1}$ from $-20{ }^{\circ} \mathrm{C}$ to $170{ }^{\circ} \mathrm{C}$ after an isothermal period of $2 \mathrm{~min}$. The modulation had 
an amplitude of $1{ }^{\circ} \mathrm{C} \min ^{-1}$ at a period of $50 \mathrm{sec}$. The melting enthalpy was determined in the total heat flow signal. Each experiment was conducted once $(n=1)$. The sample mass and melting enthalpy were corrected for the water content determined by TGA. Using the calibration fitting, the crystallinity was calculated from the determined melting enthalpy. The relative residual crystallinity was calculated by dividing it with the crystallinity of celecoxib in the physical mixtures, i.e., before exposure to the magnetic field. Degree of drug amorphization (\%) is the noncrystalline fraction calculated from the relative residual crystallinity. The melting enthalpy was determined using the TRIOS software from TA Instruments (version 5.1.1).

The theoretical onset were determined by DSC (Q-2000, TA Instruments, New Castle, DE, USA) as described elsewhere. ${ }^{52}$ The onset temperature of the heating rates were extrapolated to a heating rate of $0{ }^{\circ} \mathrm{C} \mathrm{min}^{-1}$. The extrapolated value corresponds to the respective onset temperature of the dissolution process for the three drug loadings of celecoxib in PVP. It should be noted that the determined temperatures correspond to water-free systems; and these will be lower for formulations that still contain small amounts of sorbed water due to the hygroscopicity of the polymer PVP.

High-performance liquid chromatography (HPLC) was conducted to quantify the amount of celecoxib in the physical mixtures and in the AMF-exposed tablets. ${ }^{8}$ In short, the experiments were performed using a 1260 Infinity HPLC (Agilent Technologies, Inc., USA) on a reverse-phase Luna 5U C18(2) 100 A column (length $150 \mathrm{~mm}$, diameter $4.60 \mathrm{~mm}$; Phenomenex Ltd., Germany). The experiments were performed at room temperature using a mobile phase consisting of 30\% Milli Q water and $70 \%$ ethanol (>99.7\% HPLC grade; VWR). Flow rate was set at $1 \mathrm{~mL} \mathrm{~min}^{-1}$ and a sample volume of $20 \mu \mathrm{L}$ injected. UV detection was performed at $251 \mathrm{~nm}$. Celecoxib eluted at about 2.7 min. The physical mixtures and the AMF-exposed tablets were dissolved in ethanol and 
filtered using a nylon syringe filter Q-max RR $25 \mathrm{~mm}$ with a pore size of $0.45 \mu \mathrm{m}$ (Frisenette Aps, Denmark). Each sample was injected in triplicate $(n=3)$. The sample mass was corrected for the corresponding water content determined with TGA.

In Vitro Dissolution of AMF-exposed tablets. Fasted state simulated intestinal fluid (FaSSIF) was used as a biorelevant medium to study the in vitro dissolution and was prepared according to the manufacturer's instructions (Biorelevant.com). The mixture was equilibrated for 2 hours before use and used within 48 hours of preparation. Amorphous celecoxib and conventional ASD (30 $\mathrm{wt} \%$ drug load) were prepared by melt quenching technique. ${ }^{53}$ The drug polymer ratio for the conventional ASD was selected based on the tablet resulting in maximum amorphous content induced by in situ amorphization (tablet 26, Table S3). For the ASD, the drug and polymer were weighed and mixed thoroughly using mortar and pestle. This mixture was spread in a thin layer on a sheet of aluminum foil and placed in an oven at $169^{\circ} \mathrm{C}$ for $5 \mathrm{~min}$, after which, it was removed, cooled to room temperature, and then pulverized using mortar and pestle. This process was repeated twice for the ASD and once for amorphous celecoxib.

The non-sink dissolution measurements were performed in FaSSIF using the $\mu$ DISS Profiler (Pion Inc., USA). ${ }^{54}$ Each channel was calibrated with its own standard curve prior to the experiment. For calibration, stock solutions were prepared using dimethyl sulfoxide containing either crystalline celecoxib alone or celecoxib (30 wt\%) in PVP. The standard curves were established with 6-8 concentrations by sequentially adding $5 \mu \mathrm{L}$ aliquots of the stock solution into $3 \mathrm{~mL}$ of FaSSIF maintained at $37 \pm 1{ }^{\circ} \mathrm{C}$ and stirred at $800 \mathrm{rpm}$. The standard curve showed a linear correlation $\mathrm{R}^{2} \geq 0.99$ over a range of $15-270 \mu \mathrm{g} \mathrm{mL} \mathrm{m}^{-1}$. The dissolution and solubility of all compounds was determined in FaSSIF. The path lengths $(2-20 \mathrm{~mm}$ ) of the in situ UV probes were selected based on the drug solubility in the selected medium and the expected degree of 
supersaturation. When a high solubility was anticipated, the shorter probe length $(5 \mathrm{~mm})$ was used. The medium was preheated to $37{ }^{\circ} \mathrm{C}$ prior to use in the dissolution experiment. The measurement was initiated by adding an excess of drug to the vials followed by $15 \mathrm{~mL}$ of preheated FaSSIF. A dose of $400 \mu \mathrm{g} \mathrm{mL} \mathrm{m}^{-1}$ of celecoxib was selected based on the recommended minimum dosage for rheumatoid arthritis and the intestinal fluid volume. ${ }^{55,56}$ Vials containing crystalline and amorphous celecoxib, and ASD (30 wt $\%$ drug load) were stirred using cross-bar magnetic stirrers at a speed of $200 \mathrm{rpm}$, whereas the vials with SPION containing powders were shaken at $300 \mathrm{rpm}$ to avoid interaction with the magnetic stir bar. All samples were maintained at $37 \pm 1{ }^{\circ} \mathrm{C}$ and analyzed at $1,5,10,15,20,25,30,45,60,120,180,240$, and 360 min with the UV-probes. Each experiment was run in triplicates except the AMF-exposed SPION containing tablets, which were run in duplicates. The second derivative spectra were used to determine the concentration of celecoxib in the medium over time. Maximum drug concentration $\left(C_{\max }\right)$ and time to reach $C_{\max }$ $\left(t_{\max }\right)$ were obtained by non-compartmental analysis the in vitro dissolution data. A One-way analysis of variance (ANOVA) using Tukey's multiple comparisons test was used to compare the $C_{\max }$ of various formulations. Data analysis was performed using GraphPad Prism 9.0 software (La Jolla, CA, USA). $p$ values were calculated as $0.1234(\mathrm{~ns}), 0.0332(*), 0.0021(* *), 0.0002$ $(* * *)$, and $<0.0001(* * * *)$.

\section{ASSOCIATED CONTENT}

Supporting Information. Additional figures and tables, as described in the text, include results from SPION characterization, formulation design space, summary of Design of Experiments, TEM image analysis, modelling of amorphization, and in vitro dissolution assays (Tables S1 - S2, Figures S1 - S4). 


\section{AUTHOR INFORMATION}

\section{Corresponding Author}

Alexandra Teleki - Department of Pharmacy, Science for Life Laboratory, Uppsala University, 75123 Uppsala, Sweden

E-mail: alexandra.teleki@scilifelab.uu.se

\section{Present Addresses}

†Nele-Johanna Hempel - Global Research Technologies, Novo Nordisk A/S, Novo Nordisk Park 1, 2760 Måløv, Denmark

\section{Author Contributions}

Design: S.R.A, N.J.H., K.L., A.T.; Experiments: S.R.A., N.J.H., S.A.; Data analysis: S.R.A., N.J.H.; Data visualization: S.R.A.; writing original draft preparation: S.R.A, N.J.H.; writingreview and editing: S.R.A., N.J.H., P.S., C.A.S.B., K.L., A.T. All authors have read and agreed to the published version of the manuscript. All authors have given approval to the final version of the manuscript.

\section{ACKNOWLEDGMENT}

The authors express gratitude to Dr. Georgios Sotiriou, for assistance with FSP; Dr. Reinier Oropesa-Nunez for help with the magnetometry measurements; and Dr. Caroline Alvebratt, for help with the $\mu$ DISS profiler. We acknowledge the BioVis Core Facility/Electron Microscopy node at the Department of Immunology, Genetics and Pathology, Uppsala University, for 
assistance with TEM analysis. Authors gratefully acknowledge funding from NordForsk (Nordic University Hub project No. 85352; Nordic POP) and the Independent Research Fund Denmark (Grant No. DFF-7026-00052B). The Science for Life Laboratory is gratefully acknowledged for financial support. This project has also received funding from the European Research Council (ERC) under the European Union's Horizon 2020 research and innovation programme (grant agreement No. 101002582).

\begin{abstract}
ABBREVIATIONS
SPION, superparamagnetic iron oxide nanoparticle; AMF, alternating magnetic field; ASD, amorphous solid dispersion; PVP, polyvinylpyrolidone; FSP, flame spray pyrolysis; DoE, design of experiments; XRD, x-ray diffraction; TEM, transmission electron microscopy; DSC, differential scanning calorimetry; SDS, sodium dodecyl sulfate; FaSSIF, fasted state simulated intestinal fluid; TGA, thermogravimetric analyzer; HPLC, high performance liquid chromatography.
\end{abstract}

\title{
REFERENCES
}

(1) Baghel, S.; Cathcart, H.; O'Reilly, N. J. Polymeric Amorphous Solid Dispersions: A Review of Amorphization, Crystallization, Stabilization, Solid-State Characterization, and Aqueous Solubilization of Biopharmaceutical Classification System Class II Drugs. J. Pharm. Sci. 2016, 105 (9), 2527-2544.

(2) Jermain, S. V.; Brough, C.; Williams, R. O. Amorphous Solid Dispersions and Nanocrystal Technologies for Poorly Water-Soluble Drug Delivery - An Update. Int. J. Pharm. 2018, $535(1-2), 379-392$. 
(3) He, Y.; Ho, C. Amorphous Solid Dispersions: Utilization and Challenges in Drug Discovery and Development. J. Pharm. Sci. 2015, 104 (10), 3237-3258.

(4) Vasconcelos, T.; Marques, S.; das Neves, J.; Sarmento, B. Amorphous Solid Dispersions: Rational Selection of a Manufacturing Process. Adv. Drug Deliv. Rev. 2016, 100, 85-101.

(5) Knopp, M. M.; Olesen, N. E.; Holm, P.; Löbmann, K.; Holm, R.; Langguth, P.; Rades, T. Evaluation of Drug-Polymer Solubility Curves Through Formal Statistical Analysis: Comparison of Preparation Techniques. J. Pharm. Sci. 2015, 104 (1), 44-51.

(6) Priemel, P. A.; Laitinen, R.; Grohganz, H.; Rades, T.; Strachan, C. J. In Situ Amorphisation of Indomethacin with Eudragit® E during Dissolution. Eur. J. Pharm. Biopharm. 2013, 85 (3), 1259-1265.

(7) Hempel, N. J.; Morsch, F.; Knopp, M. M.; Berthelsen, R.; Löbmann, K. The Use of Glycerol as an Enabling Excipient for Microwave-Induced In Situ Drug Amorphization. J. Pharm. Sci. 2021, $110(1), 155-163$.

(8) Hempel, N.-J.; Merkl, P.; Asad, S.; Knopp, M. M.; Berthelsen, R.; Bergström, C. A. S.; Teleki, A.; Sotiriou, G. A.; Löbmann, K. Utilizing Laser Activation of Photothermal Plasmonic Nanoparticles to Induce On-Demand Drug Amorphization inside a Tablet. Mol. Pharm. 2021, 18 (6), 2254-2262.

(9) Doreth, M.; Hussein, M. A.; Priemel, P. A.; Grohganz, H.; Holm, R.; Lopez de Diego, H.; Rades, T.; Löbmann, K. Amorphization within the Tablet: Using Microwave Irradiation to Form a Glass Solution in Situ. Int. J. Pharm. 2017, 519 (1-2), 343-351. 
(10) Edinger, M.; Knopp, M. M.; Kerdoncuff, H.; Rantanen, J.; Rades, T.; Löbmann, K. Quantification of Microwave-Induced Amorphization of Celecoxib in PVP Tablets Using Transmission Raman Spectroscopy. Eur. J. Pharm. Sci. 2018, 117, 62-67.

(11) Hempel, N.-J.; Dao, T.; Knopp, M. M.; Berthelsen, R.; Löbmann, K. The Influence of Temperature and Viscosity of Polyethylene Glycol on the Rate of Microwave-Induced In Situ Amorphization of Celecoxib. Molecules 2020, 26 (1), 110.

(12) Tiwari, D. K.; Jin, T.; Behari, J. Dose-Dependent in-Vivo Toxicity Assessment of Silver Nanoparticle in Wistar Rats. Toxicol. Mech. Methods 2011, 21 (1), 13-24.

(13) Wahajuddin; Arora, S. Superparamagnetic Iron Oxide Nanoparticles: Magnetic Nanoplatforms as Drug Carriers. Int. J. Nanomedicine 2012, 7, 3445-3471.

(14) Anselmo, A. C.; Mitragotri, S. Nanoparticles in the Clinic: An Update. Bioeng. Transl. Med. 2019, 4 (3).

(15) Laurent, S.; Dutz, S.; Häfeli, U. O.; Mahmoudi, M. Magnetic Fluid Hyperthermia: Focus on Superparamagnetic Iron Oxide Nanoparticles. Adv. Colloid Interface Sci. 2011, 166 (12), 8-23.

(16) Bauer, L. M.; Situ, S. F.; Griswold, M. A.; Samia, A. C. S. High-Performance Iron Oxide Nanoparticles for Magnetic Particle Imaging-Guided Hyperthermia (HMPI). Nanoscale 2016, 8 (24), 12162-12169.

(17) Ferjaoui, Z.; Jamal Al Dine, E.; Kulmukhamedova, A.; Bezdetnaya, L.; Soon Chang, C.; Schneider, R.; Mutelet, F.; Mertz, D.; Begin-Colin, S.; Quilès, F.; Gaffet, E.; Alem, H. 
Doxorubicin-Loaded Thermoresponsive Superparamagnetic Nanocarriers for Controlled Drug Delivery and Magnetic Hyperthermia Applications. ACS Appl. Mater. Interfaces 2019, 11 (34), 30610-30620.

(18) Gao, F.; Xie, W.; Miao, Y.; Wang, D.; Guo, Z.; Ghosal, A.; Li, Y.; Wei, Y.; Feng, S.-S.; Zhao, L.; Fan, H. M. Magnetic Hydrogel with Optimally Adaptive Functions for Breast Cancer Recurrence Prevention. Adv. Healthc. Mater. 2019, 8 (14), 1900203.

(19) Demirci Dönmez, C. E.; Manna, P. K.; Nickel, R.; Aktürk, S.; Van Lierop, J. Comparative Heating Efficiency of Cobalt-, Manganese-, and Nickel-Ferrite Nanoparticles for a Hyperthermia Agent in Biomedicines. ACS Appl. Mater. Interfaces 2019, 11 (7), 68586866.

(20) Ge, J.; Hu, Y.; Biasini, M.; Beyermann, W. P.; Yin, Y. Superparamagnetic Magnetite Colloidal Nanocrystal Clusters. Angew. Chemie Int. Ed. 2007, 46 (23), 4342-4345.

(21) Lee, J.-H.; Huh, Y.-M.; Jun, Y.; Seo, J.; Jang, J.; Song, H.-T.; Kim, S.; Cho, E.-J.; Yoon, H.-G.; Suh, J.-S.; Cheon, J. Artificially Engineered Magnetic Nanoparticles for UltraSensitive Molecular Imaging. Nat. Med. 2007, 13 (1), 95-99.

(22) Iacovita, C.; Florea, A.; Scorus, L.; Pall, E.; Dudric, R.; Moldovan, A. I.; Stiufiuc, R.; Tetean, R.; Lucaciu, C. M. Hyperthermia, Cytotoxicity, and Cellular Uptake Properties of Manganese and Zinc Ferrite Magnetic Nanoparticles Synthesized by a Polyol-Mediated Process. Nanomaterials 2019, 9 (10).

(23) Starsich, F. H. L.; Eberhardt, C.; Boss, A.; Hirt, A. M.; Pratsinis, S. E. Coercivity Determines Magnetic Particle Heating. Adv. Healthc. Mater. 2018, 7 (19), 1800287. 
(24) Warner, T. D.; Mitchell, J. A. Cyclooxygenases: New Forms, New Inhibitors, and Lessons from the Clinic. FASEB J. 2004, 18 (7), 790-804.

(25) Starsich, F. H. L.; Sotiriou, G. A.; Wurnig, M. C.; Eberhardt, C.; Hirt, A. M.; Boss, A.; Pratsinis, S. E. Silica-Coated Nonstoichiometric Nano Zn-Ferrites for Magnetic Resonance Imaging and Hyperthermia Treatment. Adv. Healthc. Mater. 2016, 5 (20), 2698-2706.

(26) Strobel, R.; Pratsinis, S. E. Flame Aerosol Synthesis of Smart Nanostructured Materials. $J$. Mater. Chem. 2007, 17 (45), 4743-4756.

(27) Mueller, R.; Mädler, L.; Pratsinis, S. E. Nanoparticle Synthesis at High Production Rates by Flame Spray Pyrolysis. Chem. Eng. Sci. 2003, 58 (10), 1969-1976.

(28) Jonasson, C.; Schaller, V.; Zeng, L.; Olsson, E.; Frandsen, C.; Castro, A.; Nilsson, L.; Bogart, L. K.; Southern, P.; Pankhurst, Q. A.; Puerto Morales, M.; Johansson, C. Modelling the Effect of Different Core Sizes and Magnetic Interactions inside Magnetic Nanoparticles on Hyperthermia Performance. J. Magn. Magn. Mater. 2019, 477, 198-202.

(29) Gonzales-Weimuller, M.; Zeisberger, M.; Krishnan, K. M. Size-Dependant Heating Rates of Iron Oxide Nanoparticles for Magnetic Fluid Hyperthermia. J. Magn. Magn. Mater. 2009, 321 (13), 1947-1950.

(30) Dadfar, S. M.; Camozzi, D.; Darguzyte, M.; Roemhild, K.; Varvarà, P.; Metselaar, J.; Banala, S.; Straub, M.; Güvener, N.; Engelmann, U.; Slabu, I.; Buhl, M.; Van Leusen, J.; Kögerler, P.; Hermanns-Sachweh, B.; Schulz, V.; Kiessling, F.; Lammers, T. Size-Isolation of Superparamagnetic Iron Oxide Nanoparticles Improves MRI, MPI and Hyperthermia Performance. J. Nanobiotechnology 2020, 18 (1), 22. 
(31) Carrey, J.; Mehdaoui, B.; Respaud, M. Simple Models for Dynamic Hysteresis Loop Calculations of Magnetic Single-Domain Nanoparticles: Application to Magnetic Hyperthermia Optimization. J. Appl. Phys. 2011, 109 (8), 083921.

(32) Kerroum, M. A. A.; Iacovita, C.; Baaziz, W.; Ihiawakrim, D.; Rogez, G.; Benaissa, M.; Lucaciu, C. M.; Ersen, O. Quantitative Analysis of the Specific Absorption Rate Dependence on the Magnetic Field Strength in $\mathrm{Zn}_{\mathrm{x}} \mathrm{Fe}_{3-\mathrm{x}} \mathrm{O}_{4}$ Nanoparticles. Int. J. Mol. Sci. 2020, $21(20), 1-24$.

(33) Mohapatra, J.; Mitra, A.; Bahadur, D.; Aslam, M. Surface Controlled Synthesis of $\mathrm{MFe}_{2} \mathrm{O}_{4}$ $(\mathrm{M}=\mathrm{Mn}, \mathrm{Fe}, \mathrm{Co}, \mathrm{Ni}$ and $\mathrm{Zn})$ Nanoparticles and Their Magnetic Characteristics. CrystEngComm 2013, 15 (3), 524-532.

(34) Teleki, A.; Suter, M.; Kidambi, P. R.; Ergeneman, O.; Krumeich, F.; Nelson, B. J.; Pratsinis, S. E. Hermetically Coated Superparamagnetic $\mathrm{Fe}_{2} \mathrm{O}_{3}$ Particles with $\mathrm{SiO}_{2}$ Nanofilms. Chem. Mater. 2009, 21 (10), 2094-2100.

(35) Choi, Y. S.; Young Yoon, H.; Sung Lee, J.; Hua Wu, J.; Keun Kim, Y. Synthesis and Magnetic Properties of Size-Tunable $\mathrm{Mn}_{x} \mathrm{Fe}_{3-\mathrm{x}} \mathrm{O}_{4}$ Ferrite Nanoclusters. J. Appl. Phys. 2014, 115 (17), $17 \mathrm{~B} 517$.

(36) Srivastava, M.; Alla, S. K.; Meena, S. S.; Gupta, N.; Mandal, R. K.; Prasad, N. K. $\mathrm{Zn}_{\mathrm{X}} \mathrm{Fe}_{3-\mathrm{x}} \mathrm{O}_{4}(0.01 \leq \mathrm{x} \leq 0.8)$ Nanoparticles for Controlled Magnetic Hyperthermia Application. New J. Chem. 2018, 42 (9), 7144-7153.

Doaga, A.; Cojocariu, A. M.; Amin, W.; Heib, F.; Bender, P.; Hempelmann, R.; Caltun, O. F. Synthesis and Characterizations of Manganese Ferrites for Hyperthermia Applications. 
Mater. Chem. Phys. 2013, 143 (1), 305-310.

(38) Strobel, R.; Pratsinis, S. E. Direct Synthesis of Maghemite, Magnetite and Wustite Nanoparticles by Flame Spray Pyrolysis. Adv. Powder Technol. 2009, 20 (2), 190-194.

(39) Vemury, S.; Pratsinis, S. E. Self-Preserving Size Distributions of Agglomerates. J. Aerosol Sci. 1995, 26 (2), 175-185.

(40) Lasheras, X.; Insausti, M.; De La Fuente, J. M.; Gil De Muro, I.; Castellanos-Rubio, I.; Marcano, L.; Fernández-Gubieda, M. L.; Serrano, A.; Martín-Rodríguez, R.; Garaio, E.; García, J. A.; Lezama, L. Mn-Doping Level Dependence on the Magnetic Response of $\mathrm{Mn}_{\mathrm{x}} \mathrm{Fe}_{3-\mathrm{x}} \mathrm{O}_{4}$ Ferrite Nanoparticles. Dalt. Trans. 2019, 48 (30), 11480-11491.

(41) Behdadfar, B.; Kermanpur, A.; Sadeghi-Aliabadi, H.; Morales, M. D. P.; Mozaffari, M. Synthesis of Aqueous Ferrofluids of $\mathrm{Zn}_{\mathrm{x}} \mathrm{Fe}_{3-\mathrm{x}} \mathrm{O}_{4}$ Nanoparticles by Citric Acid Assisted Hydrothermal-Reduction Route for Magnetic Hyperthermia Applications. J. Magn. Magn. Mater. 2012, 324 (14), 2211-2217.

(42) Rosensweig, R. E. Heating Magnetic Fluid with Alternating Magnetic Field. J. Magn. Magn. Mater. 2002, 252 (1-3 SPEC. ISS.), 370-374.

(43) Roudaut, G.; Simatos, D.; Champion, D.; Contreras-Lopez, E.; Le Meste, M. Molecular Mobility around the Glass Transition Temperature: A Mini Review. Innov. Food Sci. Emerg. Technol. 2004, 5 (2), 127-134.

(44) Rask, M. B.; Knopp, M. M.; Olesen, N. E.; Holm, R.; Rades, T. Comparison of Two DSCBased Methods to Predict Drug-Polymer Solubility. Int. J. Pharm. 2018, 540 (1-2), 98 
105.

(45) Noyes, A. A.; Whitney, W. R. The Rate of Solution of Solid Substances in Their Own Solutions. J. Am. Chem. Soc. 1897, 19 (12), 930-934.

(46) Böhmert, L.; Niemann, B.; Thünemann, A. F.; Lampen, A. Cytotoxicity of Peptide-Coated Silver Nanoparticles on the Human Intestinal Cell Line Caco-2. Arch. Toxicol. 2012, 86 (7), $1107-1115$.

(47) Voss, L.; Hoché, E.; Stock, V.; Böhmert, L.; Braeuning, A.; Thünemann, A. F.; Sieg, H. Intestinal and Hepatic Effects of Iron Oxide Nanoparticles. Arch. Toxicol. 2021, 95 (3), 895-905.

(48) Martínez-Rodríguez, N. L.; Tavárez, S.; González-Sánchez, Z. I. In Vitro Toxicity Assessment of Zinc and Nickel Ferrite Nanoparticles in Human Erythrocytes and Peripheral Blood Mononuclear Cell. Toxicol. Vitr. 2019, 57, 54-61.

(49) Knopp, M. M.; Nguyen, J. H.; Becker, C.; Francke, N. M.; Jørgensen, E. B.; Holm, P.; Holm, R.; Mu, H.; Rades, T.; Langguth, P. Influence of Polymer Molecular Weight on in Vitro Dissolution Behavior and in Vivo Performance of Celecoxib:PVP Amorphous Solid Dispersions. Eur. J. Pharm. Biopharm. 2016, 101, 145-151.

(50) Vasconcelos, T.; Sarmento, B.; Costa, P. Solid Dispersions as Strategy to Improve Oral Bioavailability of Poor Water Soluble Drugs. Drug Discov. Today 2007, 12 (23-24), 1068 1075.

(51) Guzmán, H. R.; Tawa, M.; Zhang, Z.; Ratanabanangkoon, P.; Shaw, P.; Gardner, C. R.; 
Chen, H.; Moreau, J. P.; Almarsson, Ö.; Remenar, J. F. Combined Use of Crystalline Salt Forms and Precipitation Inhibitors to Improve Oral Absorption of Celecoxib from Solid Oral Formulations. J. Pharm. Sci. 2007, 96 (10), 2686-2702.

(52) Hempel, N. J.; Merkl, P.; Knopp, M. M.; Berthelsen, R.; Teleki, A.; Sotiriou, G. A.; Löbmann, K. The Influence of Drug-Polymer Solubility on Laser-Induced in Situ Drug Amorphization Using Photothermal Plasmonic Nanoparticles. Pharmaceutics 2021, 13 (6), 917.

(53) Wendelboe, J.; Knopp, M. M.; Khan, F.; Chourak, N.; Rades, T.; Holm, R. Importance of in Vitro Dissolution Conditions for the in Vivo Predictability of an Amorphous Solid Dispersion Containing a PH-Sensitive Carrier. Int. J. Pharm. 2017, 531 (1), 324-331.

(54) Andersson, S. B. E.; Alvebratt, C.; Bevernage, J.; Bonneau, D.; da Costa Mathews, C.; Dattani, R.; Edueng, K.; He, Y.; Holm, R.; Madsen, C.; Müller, T.; Muenster, U.; Müllertz, A.; Ojala, K.; Rades, T.; Sieger, P.; Bergström, C. A. S. Interlaboratory Validation of SmallScale Solubility and Dissolution Measurements of Poorly Water-Soluble Drugs. J. Pharm. Sci. 2016, 105 (9), 2864-2872.

(55) Butler, J. M.; Dressman, J. B. The Developability Classification System: Application of Biopharmaceutics Concepts to Formulation Development. J. Pharm. Sci. 2010, 99 (12), 4940-4954.

(56) Clemett, D.; Goa, K. L. Celecoxib: A Review of Its Use in Osteoarthritis, Rheumatoid Arthritis and Acute Pain. Drugs 2000, 59 (4), 957-980. 


\section{FOR TABLE OF CONTENTS ONLY}

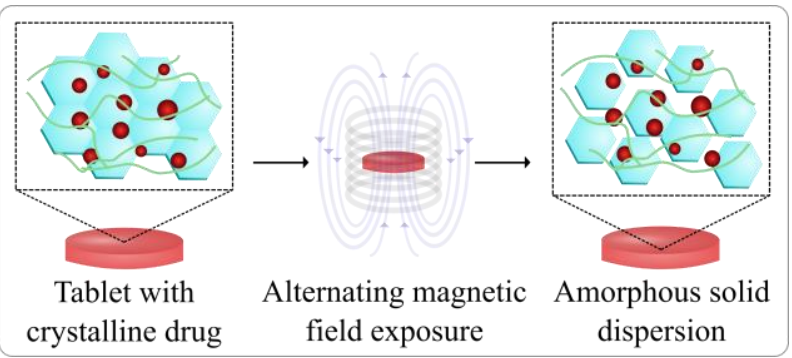

